\title{
Língua \\ e Literatura Latina
}

\section{A. A. PETERLINI}

$\mathrm{N}$ o dia 25 de janeiro de 1937, no anfiteatro da Faculdade de Medicina da USP, formava-se a primeira turma de licenciados da Faculdade de Filosofia, Ciências e Letras, que fora fundada em 25 de janeiro de 1934 pelo decreto estadual no 6.283. Dos 26 alunos que colaram grau nessa solenidade, apenas dois pertenciam à subsegão de Letras Clássicas e Portugues -, remanescentes dos cinco matriculados em 1934. O problema da malsinada evasão parece congênito à Faculdade. $E$ a preocupaçăo em justificar perante a sociedade brasileira disciplinas de cunho formativo humanístico náo é menos antiga: o Dr. Antonio de Almeida Prado, no discurso com que abriu a cerimônia de formatura, escudava-se em Macauly, para asseverar "que os homens que se ocupam até os vinte anos de idade em estudos que não se correlacionam, de maneira imediata, com o exercício ou com o interesse de nenhuma profissão, sobrepujam na prática aos que, em condiçóes idênticas, se dedicam a assuntos de caráter profissional..." No comedimento das palavras em que desenvolve suas idéias, Dr. Almeida Prado - e o sonho deve ter sido comum aos fundadores da Faculdade - não alcança disfarçar a esperança de que a nova Instituiçáo possa oferecer, um dia, quem sabe, ao Brasil, um "corpo de cidadáos doutos e impolutos, colaboradores permanentes dos políticos..., sobranceiros às mudanças ministeriais $\mathrm{e}$ às crises governamentais, acima da corrupção e da venalidade partidárias..." Sonho apenas?! O porte atual das três universidades paulistas não seria uma atualização daquele anseio?!...

Entre as disciplinas não imediatamente ligadas ao profissional, estava Língua e Literatura Latina.

\section{Os professores estrangeiros}

Um dos mestres europeus que o professor Teodoro Ramos, por incumbência do governo do estado, trouxe em 1934, para lecionar na FFCL, o professor Michel Berveiller, veio para Latim - Cátedras de Língua e Literatura Latina e Literatura Grega. Nascido em Sommedieue (Meuse-França), em 16 de julho de 1910; bacharel em Letras (latim e grego) em 1925; em Filosofia, em 1926; aluno da Escola Normal Su- 
perior de 1928 a 1931; licenciado em Letras em 1929. Percorreu em viagens de estudo a Inglaterra, a Itália, a Grécia e a Turquia. Agregé da Universidade de Paris, em 1931, professor de Letras em Dijon, de 1932 a 1934.

Iniciava-se, pois, a disciplina de Língua e Literatura Latina na FFCL da USP - um professor de excelente cabedal de conhecimentos e cinco alunos - em 1934.

Professor Berveiller ficou conosco até 1937, secundado algum tempo pelo renome do professor de Filologia Portuguesa, Rebelo Gonçalves, em cujas mãos ficaram o grego e o latim em 1937, quando Berveiller nos deixou, retornando à Europa.

$\mathrm{Na}$ aula inaugural das Cadeiras de Filologia Grega e Latina e Literatura Grega e Latina, em 21 de março de 1937, o professor Rebelo Gonçalves declarava: "Volto, afinal, aonde sempre deveria estar, e donde só poderia afastar-me, com generosos auspícios, a magnânima fidalguia de São Paulo... retorno ao grego e ao latim, as disciplinas a cujo ensino ascendi por concurso na Faculdade de Letras de Lisboa; em cuja vigilância e defesa recebi a herança de Antonio José Viale, Epifânio Dias, José Maria Rodrigues, José Joaquim Nunes, e cuja matéria, para mais dobrado exercício, ainda preenche a maior parte dos meus deveres noutro baluarte de estudos filológicos, a secular Academia de Portugal."

O professor Rebelo Gonçalves, uma das honras do latim e do grego na Faculdade de Filosofia, Letras e Ciências Humanas da USP, ficou um ano apenas nessa cadeira, o suficiente para que a Faculdade pudesse, para seu próprio desvanecimento, por-lhe o busto no átrio de suas gratas lembranças.

Sucederam-no, e também por um ano, os professores Atílio Venturini para Filologia Grega e Latina, e George Readers, contratados em 1938 e 1937, respectivamente, este último como auxiliar de ensino de Literatura Francesa, ajudou em Filologia e Literatura Latina em 1938.

Chegava de Portugal, em 1939, o professor Urbano Canuto Soares, doutor em Letras, contratado para Latim, a partir de $1 \%$ de março. Aqui permaneceu até o final de 1954, quando retornou à sua pátria.

\section{A orientação dada ao latim}

O Anuário da FFCL dos anos de 1939 a 1949 traz algumas linhas sobre a orientaçáo dada à disciplina pelo professor Canuto: "Desde o princípio preocupou-se o professor Urbano Soares com imprimir ao ensino superior da Cadeira de Língua e Literatura Latina, uma orien- 
tação moderna, seguindo sempre o critério histórico-comparativo no estudo dos fatos da língua e fundamentando o conhecimento das questôes de História da Literatura nos textos literários..."

Mil novecentos e quarenta abre o caminho para os brasileiros, na área de Língua e Literatura Latina. Professor Theodoro Henrique Maurer Jr. foi assistente do professor Canuto até 31 de dezembro de 1946. Em 1944, entra como auxiliar de ensino o professor Armando Tonioli, que passaria a primeiro assistente em 1948, em 1955 assumiria como catedrático interno e, em 1962, como contratado. Ficou à frente da disciplina de Língua e Literatura Latina até 2 de março de 1970, quando faleceu. Foi o primeiro brasileiro contratado como catedrático de Língua e Literatura Latina na FFLCH da USP.

A herança principal que nos legou o professor Tonioli está no interesse pelos estudos da história da língua latina, mormente no que tange à fonética e à morfologia, área em que foi professor exímio. Também não vai esquecer nunca, nós que lhe assistiram às aulas, o grande amor à precisão no traduzir os textos latinos - era quase de ourives o cuidado com que buscava o exato correspondente do termo latino em português.

A partir daí, sob a coordenaçáo orientadora de outros professores, ainda vivos, os estudos de língua latina e, até certo ponto, os de literatura latina tiveram de ajustar-se, de força, ao crescente desconhecimento do latim dos novos universitários, legítimo presente de grego dos programas oficiais aos futuros alunos de Letras.

Mas, com o desenvolvimento da pós-graduação, é hoje possível à disciplina conduzir pesquisas e trabalhos de bom nível, que pós-graduandos, alguns de outros estados do Brasil, têm levado a bom termo, já em dissertaçóes de mestrado, já em teses de doutoramento, que se transformam, às vezes, em publicações excelentes. Com uma média de 35 alunos, a pós-graduaçáo em Língua e Literatura Latina da FFLCH vem conseguindo formar bons professores e pesquisadores sérios.

A área de Latim conta hoje com 11 professores: um titular, cinco doutores, quatro mestres e dois auxiliares de ensino, todos formados na FFLCH da USP.

\section{Os cursos atuais}

Os trabalhos docentes da graduação dividem-se atualmente por numerosíssimas classes de currículo-mínimo, esse maltrapilho equivalente para letras, das biológicas para medicina e das exatas para enge- 
nharia. Mas sempre vale como espertador de vocaçóes para os estudos clássicos greco-latinos.

O curso básico de Língua e Literatura Latina estende-se por quatro anos, com uma média de seis a oito aulas semanais. Bons alunos têm alcançado ótimos níveis para o ingresso na pós-graduação.

As experiências metodológicas no ensino da língua latina, deixadas à livre escolha dos professores, permitiram que a área de Latim possa agora opinar sobre várias iniciativas assim européias como norte-americanas. Merece ser lembrada, pelo longo uso, uma adaptaçäo do Método de Sweet: Latin - a structural approach.

A tradução e análise do texto a várias luzes distribui-se entre passagens mais significativas da poesia e da prosa latina, apoiando de alguma forma os estudos de Literatura Latina.

\section{A pesquisa}

É, porém, na pós-graduaçáo que se desenvolve a pesquisa já de docentes, já de orientandos. Sem requintes classificatórios, mas visando apenas a informar, relatam-se aqui algumas linhas e trabalhos dessa pesquisa, completos ou em andamento. Assim, nas linhas de:

- estrutura da frase latina, há estudos sobre as subordinadas completivas, sobre as formas nominais do verbo latino, sobre os nexos transfrásicos na prosa latina clássica, sobre a interrogaçáo e sobre a correlaçáo em latim;

- pensamento filosofico greco-latino, desenvolveram-se ou se desenvolvem estudos a respeito da poesia didática e o epicurismo em Lucrécio; sobre o quarto canto das Geórgicas; o De fato de Cícero; o De clementia, as Cartas a Lucilio e As consolafóes de Sêneca;

- do teatro greco-latino, há trabalhos sobre Teatro clássico e modernidade, sobre o teatro de Sêneca: As troianas, Tiestes, Fedra, Édipo rei e Otdávia (Pseudo Sêneca); do teatro de Terêncio, foi estudada a peça Hecyra e, do de Plauto, a dos Menaechmi;

- Iirica greco-latina, foram objeto de pesquisa, ou ainda o são, Catulo, sob vários aspectos; Tibulo, Propércio, Horácio e As bucólicas de Vergílio;

- narrativa greco-latina desenvolve ou desenvolveu pesquisas sobre Salústio, César, Tácito e Tito Lívio; 
- sdtira latina, foram estudados o humor latino no Satyricon, e $A$ Ceia de Trimalquitio; está em andamento um trabalho sobre As sdtiras de Juvenal;

- retórica greco-lativa, há pesquisas sobre a Rhetorica ad berennium, sobre a retórica em Cícero e a Arte Póttica de Horácio.

Dessas pesquisas, algumas se tornaram cursos; algumas, dissertaçóes de mestrado; outras, teses de doutoramento. Há as que foram publicadas e estáo nas livrarias em livros ou em revistas de divulgação científica.

\section{As publicações}

Um projeto de publicaçáo de textos - Antologia billngüue de escritores latinos - já logrou editar a Livica latina, uma antologia que permite ao leitor conhecimento razoável nesse âmbito da poesia latina. Encontra-se no prelo a terceira ediçáo de textos de História e, em andamento, a Antologia da épica latina.

Na tentativa de prestar ajuda à comunidade, a área de Língua e Literatura Latina mantém ainda um curso de extensão universitária, consagrado ao ensino do latim, em seis semestres, para os interessados que nâo podem cursar o básico de latim em Letras. A freqüência sáncionou o valor desse trabalho.

\section{Os contatos culturais}

Para manter contato com o Primeiro Mundo e com as próprias origens, professores europeus, italianos e franceses principalmente, têm sido convidados para cursos e conferências, o que permite, além do proveito científico, uma avaliaçáo do que temos conseguido na FFLCH.

Encontros culturais com colegas da área de todo o Brasil e de alguns países da América Latina, em especial da Argentina, nas reuniōes anuais da Sociedade Brasileira de Estudos Clássicos, são em extremo úteis. Não menor proveito tem advindo das participaçōes dos professores de Língua e Literatura Latina da USP em congressos de Letras Clássicas em outros países, como Argentina, Cuba, Venezuela, Uruguai e Canadá.

Não obstante o sem-número de obstáculos que sobrevieram ao ensino no Brasil, nas últimas décadas, a área de Língua e Literatura Latina da FFLCH da USP poderia hoje, sem dúvida, apresentar-se pelos 
poderes da imaginaçáo naquela primeira classe de cinco alunos do professor Berveiller, de 1934, na modesta sala tomada de empréstimo à Faculdade de Medicina, e responder em medido orgulho e gratidão: ADSUM !

A. A. Peterlini é professor do Departamento de Letras Clássicas e Vernáculas da Faculdade de Filosofia, Letras e Ciências Humanas da USP. 